\title{
CARACTERIZAÇÃO ANATÔMICA FOLIAR PARA 14 ESPÉCIES DE XYRIS L. (XYRIDACEAE) DA SERRA DO CIPÓ, MG, BRASIL
}

\author{
Maria das Graças Sajo ${ }^{1}$ \\ Maria das Graças Lapa Wanderley² \\ Luciana Marques de Carvalho ${ }^{3}$
}

Recebido em 09.05.94. Aceito em 02.03.95.

RESUMO - (Caracterização anatômica foliar para 14 espécies de Xyris L. (Xyridaceae) da Serra do Cipó, MG, Brasil). As folhas de $X$. anamariae, $X$. archeri, $X$. hymenachne, $X$. melanopoda, $X$. minarum, X. obcordata, X. paraensis, X. pilosa, X. platystachia, X. pterygoblephara, X. savanensis, $X$. spinulosa, $X$. tortilis e $X$. tortula, foram preparadas segundo técnicas usuais para estudos anatômicos. A análise comparativa, da região basal desses órgãos, mostrou diferenças na estrutura da epiderme, na organização do mesofilo e no número e grau de agrupamento dos feixes vasculares, dependendo da espécie considerada. Esses aspectos foram utilizados na caracterização de cada representante estudado e, analisados em conjunto para indicar formas diferentes de especialização foliar, relacionadas à deficiência hídrica.

Palavras-chave: Xyris; Xyridaceae; anatomia foliar.

\begin{abstract}
Leaf anatomical features of 14 Xyris L (Xyridaceae) species from Serra do Cipó, MG, Brazil). The leaves of $X$. anamariae, $X$. archeri, $X$. hymenachne, $X$. melanopoda, $X$. minarum, $X$. obcordata, X. paraensis, X. pilosa, X. platystachia, X. pterygoblephara, X. savanensis, X. spinulosa, $X$. tortilis e $X$. tortula were prepared with the usual methods for anatomical studies. The comparative analysis of the blade base showed differences in the epidermis structure, in the mesophill organization and in the vascular bundles number and fusion, according to the species. These features were used to characterize each species and when combined they may be used to demonstrate leaf specialization forms, related to hydric deficiency.
\end{abstract}

Key words: Xyris; Xyridaceae; leaf anatomy.

\section{Introdução}

A Serra do Cipó está localizada a cerca de $110 \mathrm{Km}$ a nordeste de Belo Horizonte, Minas Gerais, sendo que grande parte da região passou a constituir o

\footnotetext{
' IBUNESP - Caixa Postal 199, 13506-900 Rio Claro-SP

${ }^{2}$ IBt - Caixa Postal 4005, 01061-970 São Paulo-SP $\quad{ }^{3}$ Pós-graduanda. Botânica - UFV - Viçosa-MG
} 
Parque Nacional da Serra do Cipó, garantindo a preservação das espécies vegetais e animais e abrindo novos horizonte para a pesquisa nesta região.

É freqüente na Serra do Cipó uma vegetação típica, de "campos rupestres", com a presença de um estrato herbáceo contínuo, constituído principalmente por espécies das famílias Xyridaceae, Eriocaulaceae, Gramineae e Cyperaceae, destacando-se também arbustos e subarbustos esparsos, das famílias Velloziaceae, Compositae, Melastomataceae, Leguminosae e Vochysiaceae (Giulietti et al. 1987).

A família Xyridaceae reúne 5 gêneros Aratitiyopea, Achlyphylla, Abolboda, Orectanthe e Xyris (-Kral 1988)-, sendo este último o maior, com cerca de 300 espécies distribuídas predominantemente nas Américas e ocorrendo, também, na Austrália, África e Índia (Wanderley 1992).

As espécies de Xyris habitam, preferencialmente, terrenos brejosos das regiões tropicais e subtropicais (Tomlinson 1969), sendo bastante freqüentes nos campos rupestres da Cadeia do Espinhaço (Minas Gerais e Bahia) e na Serra Geral de Goiás (Wanderley 1992).

Smith \& Downs (1968) reconheceram 115 espécies de Xyris para o Brasil, com a ocorrência de 28 taxa na Serra do Cipó. Mais recentemente, Wandereley (1992) referiu 42 espécies para essa região, além de 4 variedades e 1 subespécie. Destas, 4 espécies e 1 subespécie são novas.

Dentre os poucos estudos anatômicos para o gênero Xyris, destacam-se os de Carlquist (1960), Tomlinson (1969) e Sajo (1989, 1992 a e b), que apontam vários caracteres diagnósticos úteis na separação das espécies do gênero. Wanderley (1992) num estudo taxonômico das espécies de Xyris da Serra do Cipó, considera importante a anatomia foliar, na delimitação desses taxa.

Este trabalho tem como objetivo caracterizar anatomicamente as folhas de 14 espécies de Xyris e apontar formas de especialização foliar, observadas nesses representantes.

\section{Material e métodos}

O material foi coletado na Serra do Cipó e encontra-se depositado nos herbários do Instituto de Botânica (SP) e/ou do IBUNESP - Rio Claro (HRCB).

Xyris anamariae Wanderley. col. Scatena, V.L. \& Lemos-Filho, J.P. 08/06/92 (SP). Xyris archeri Smith \& Downs. Col. Sajo, M.G. \& Carvalho, L.M. 05/10/91, (HRCB 16709).

Xyris hymenachne Mart. Col. Sajo, M.G.; Machado, S.R. \& Lovato, M.B. 25/02/92, (HRCB 16671).

Xyris melanopoda Smith \& Downs. Col. Sajo, M.G. \& Carvalho, L.M. 05/10/91, (HRCB 16710).

Xyris minarum Seubert. Col. Wanderley, M.G.L. \& Sajo, M.G. 1991, (HRCB 16700). Xyris obcordata Kral \& Wanderley. Col. Sajo, M.G., Machado, S.R. \& Lovato, M.B., 25/02/92 (HRCB 16677).

Xyris paraensis Poepp. Col. Sajo, M.G., Machado, S.R. \& Lovato, M.B., 25/02/92 
(HRCB 16694).

Xyris pilosa Kunth. Col. Sajo, M.G. \& Carvalho, L.M. 05/10/91, (HRCB 16713); Col. Wanderley, M.G.L. \& Sajo, M.G. 23/11/1991, (HRCB 16699).

Xyris platystachia Alb. Nilsson. Col. Scatena, V.L. \& Lemos-Filho, J.P. 08/06/92 (SP).

Xyris pterygoblephara Steud Col. Wanderley, M.G.L. \& Sajo, M.G. 1990, (HRCB 16682); Col. Sajo, M.G., Machado, S.R. \& Lovato, M.B. 25/02/92, (HRCB 16670). Xyris savanensis Miq. Col. Wanderley, M.G.L. \& Sajo, M.G. 1970. 23/11/92. (HRCB 16688).

Xyris spinulosa Kral \& Smith. Col. Braga, M.M. 31-B 03/92. (SP).

Xyris tortilis Wanderley. Col. Wanderley, M.G.L. \& Sajo, M.G. 1969, 23/11/91 (SP). Xyris tortula Mart. Col. Sajo, M.G. \& Carvalho, L.M., 05/10/91. (HRCB 16709).

Os cortes para análise anatômica foram obtidos à mão-livre, de folhas maduras do sexto nó fixadas em FAA (Johansen 1940), e submetidos ao processo de dupla coloração com verde-iodo acético e vermelho-congo (Dop \& Gautié 1909). Os desenhos foram executados ao microscópio óptico, com o emprego da câmara-clara e projeção da escala micrométrica. Os detalhes anatômicos foram registrados através de fotomicrografias, obtidas ao microscópio Olympus.

\section{Resultados}

As figuras 1-14 representam diagramas de cortes transversais à região basal do limbo foliar deX. platystachia (Fig. 1),X. pterygoblephara (Fig. 2), X. tortilis (Fig. 3), X.obcordata (Fig. 4), X. savanensis (Fig. 5), X. hymenachne (Fig. 6), X. paraensis (Fig. 7), X. melanopoda (Fig. 8), X. archeri (Fig. 9), X. pilosa (Fig. 10), X. spinulosa (Fig. 11), X. anamariae (Fig. 12), X. tortula (Fig. 13) e X. minarum (Fig. 14).

Notam-se limbos ensiformes (Fig. 1-10), às vezes com contornos sinuosos (Fig. 5-7), e cilíndricos (Fig. 11-14), cujos feixes vasculares (setas) podem estar organizados paralelamente em 2 séries (Fig. 2), em 1-2 séries (Fig. 1 e 3) ou numa única série (Fig. 4-10) ao longo da lâmina. Observa-se, também, que o limbo de algumas espécies (Fig. 8 e 10) apresentam predominantemente feixes agrupados por bainha esclerênquimática espessa (setas), formando unidades vasculares compostas, enquanto que em outras (Fig. 1-7, 9 e 11-12) os feixes são na sua maioria livres (setas), constituindo unidades vasculares simples. As figuras 13-14 mostram limbos, com número equivalente de unidades vasculares simples e compostas.

No caso de lâminas ensiformes as unidades vasculares, presentes na região dos bordos, podem ser iguais entre si (Fig. 2-3 e 5-8) e do tipo simples (Fig. 2, 3 e 6) ou composto (Fig. 5 e 7-8). No caso das figuras 1,4 e 9-10, as unidades vasculares presentes nos bordos são diferentes entre si e representadas por uma unidade composta e outra simples. Chama-se, ainda, atenção para a presença de parênquima aqüífero (Fig. 8, setas).

Nas figuras 15-18 observam-se, em detalhe, um dos bordos e parte da região mediana do limbo de X. pilosa (Fig. 15), X. paraensis (Fig. 16), X. archeri (Fig. 17) e 


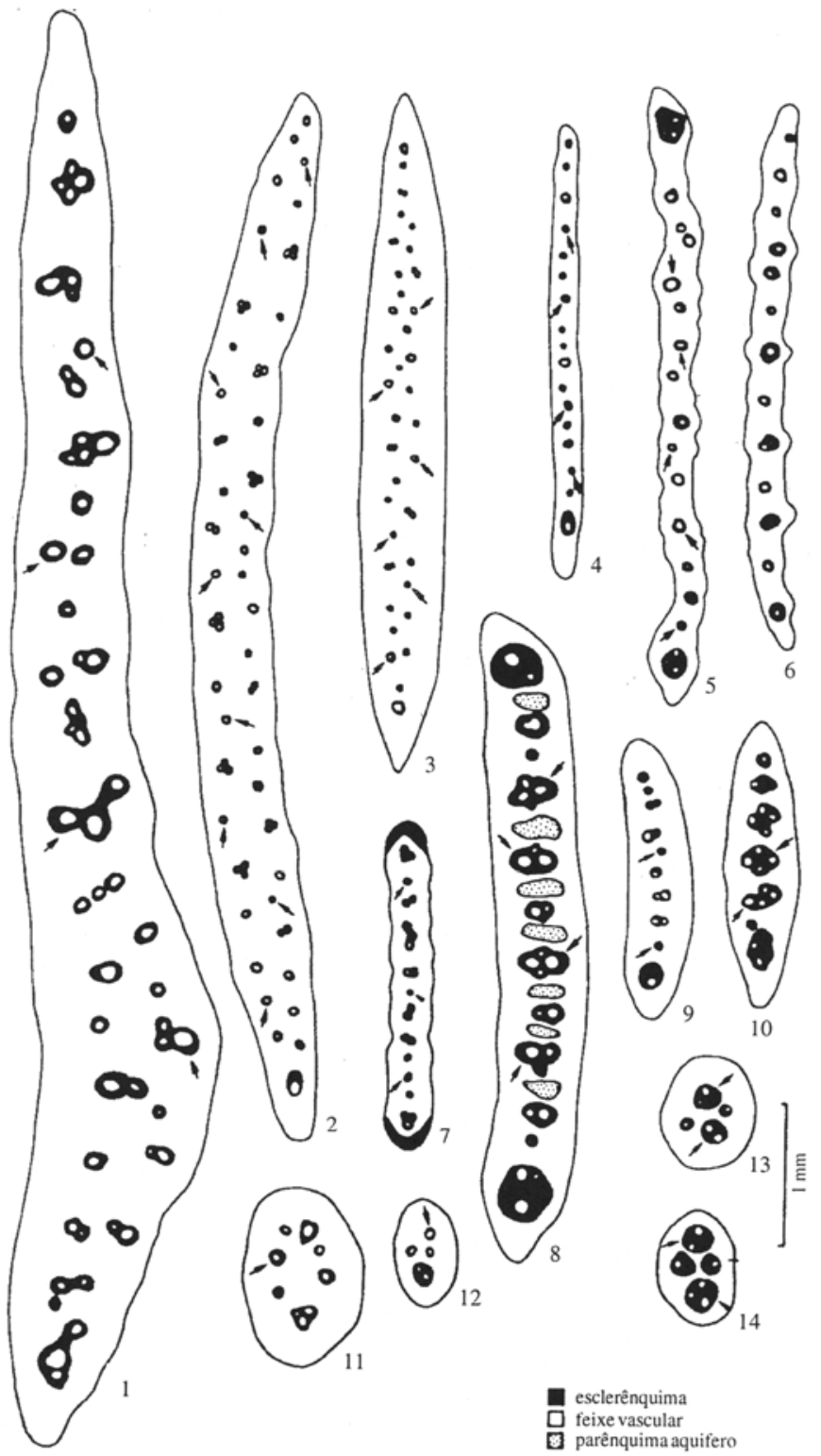

Figuras 1-14. Diagramas de cortes transversais efetuados na região basal do limbo de Xyris platystachia (Fig. 1), X. pterygoblephara (Fig. 2), X. obcordata (Fig. 4), X. savanensis (Fig. 5), X. hymenachne (Fig. 6), X. paraensis (Fig. 7), X. melanopoda (Fig. 8), X. archeri (Fig. 9), X. pilosa (Fig. 10), X. spinulosa (Fig. 11), $X$. anamariae (Fig. 12), X. tortula (Fig. 13) e X. minarum (Fig. 14). Notam-se lâminas ensiformes e cilíndricas, cujos feixes vasculares (setas) podem se apresentar livres ou reunidos por bainha esclerenquimática. 
X. savanensis (Fig. 18), em corte transversal. Notam-se, na região do bordo, células epidérmicas de paredes bastante espessadas e tricomas tectores (Fig. 17), apenas tricomas tectores (Fig. 15), células epidérmicas semelhantes às demais (Fig. 18) e várias camadas de células esclerificadas (Fig. 16). Na região mediana, as células epidérmicas podem apresentar tamanhos variáveis (Fig. 16 e 18) ou uniforme com espessamento (parede+cutícula) mais evidente nas paredes periclinais externas (Fig. 15 e 17). Em X. pilosa, X. paraensis e X. archeri, o mesofilo é formado por uma camada de parênquima paliçádico, pouco desenvolvido, junto à epiderme, e algumas camadas de parênquima esponjoso na região central (Fig. 15-17).

As figuras 19-22 representam detalhes de cortes transversais dos limbos de $X$. minarum, X. tortula, X. anamariae e $X$. spinulosa, respectivamente. Em todas as espécies a epiderme é formada por células de tamanho regular, cujas paredes podem ser uniformemente espessadas (Fig. 22) ou com espessamento periclinal externo mais pronunciado (Fig. 19-21). Em uma das extremidades do limbo podem ocorrer tricomas tectores (Fig. 19) ou células epidérmicas de paredes mais espessadas do que as demais (Fig. 21). O mesofilo é formado por uma camada de parênquima paliçádico, junto à epiderme, e parênquima esponjoso na região central (Fig. 19-21) e por 2-3 camadas de parênquima paliçádico pouco desenvolvido, junto à epiderme, e parênquima esponjoso na região central (Fig. 22).

As figuras 23-26 representam detalhes da região mediana do limbo foliar de $X$. melanopoda (Fig. 23), X. tortilis (Fig. 24), X. pterigoblephara (Fig. 25) e X. platystachia (Fig. 26). A epiderme é formada por células regulares (Fig. 23-24 e 26) ou de tamanhos diferentes (Fig. 25-26), e o espessamento parietal+cutícula pode ser uniforme (Fig. 24 e 26) ou mais proeminente nas paredes periclinais externas (Fig. 23 e 25). O mesofilo, predominante lacunoso na figura 26, pode apresentar parênquima aqüífero na região central (Fig. 23, setas), ser formado apenas por células braciformes (Fig. 25) ou conter 1-2 camadas de células em paliçada em contato com a epiderme (Fig. 24).

Detalhes de cortes transversal e longitudinal do limbo foliar de $X$. savanensis, podem ser observados, respectivamente, nas figuras 27-28. As células epidérmicas, que na figura 27 se apresentam irregulares, exibem projeções supraepidérmicas observadas melhor na figura 28 (setas). O mesofilo é formado por uma camada de parênquima paliçádico, pouco desenvolvido, e células braciformes com muitos espaços entre si, na região central (Fig. 27-28).

As figuras 29-30 representam detalhes da região mediana do limbo foliar de $X$. hymenachne e $X$. obcordata. Na primeira, a epiderme é formada por células regulares com espessamento parietal+cutícula uniforme (Fig. 29) e, na segunda este é mais pronunciado nas paredes periclinais externas (Fig. 30). O mesofilo é predominantemente lacunoso (Fig. 29-30) e o limbo apresenta contorno irregular na figura 29.

As figuras 31-35 correspondem a detalhes de feixes vasculares, observados nos limbos de X. melanopoda (Fig. 31), X. pilosa (Fig. 32), X. obcordata (Fig. 33), X. savanensis (Fig. 34) e X. pterigoblephara (Fig. 35), respectivamente.

Nas figuras 31-32 notam-se unidades vasculares compostas por 3 feixes (Fig. 31) ou 4 feixes (Fig. 32), agrupados por células de paredes esclerificadas. Externa- 

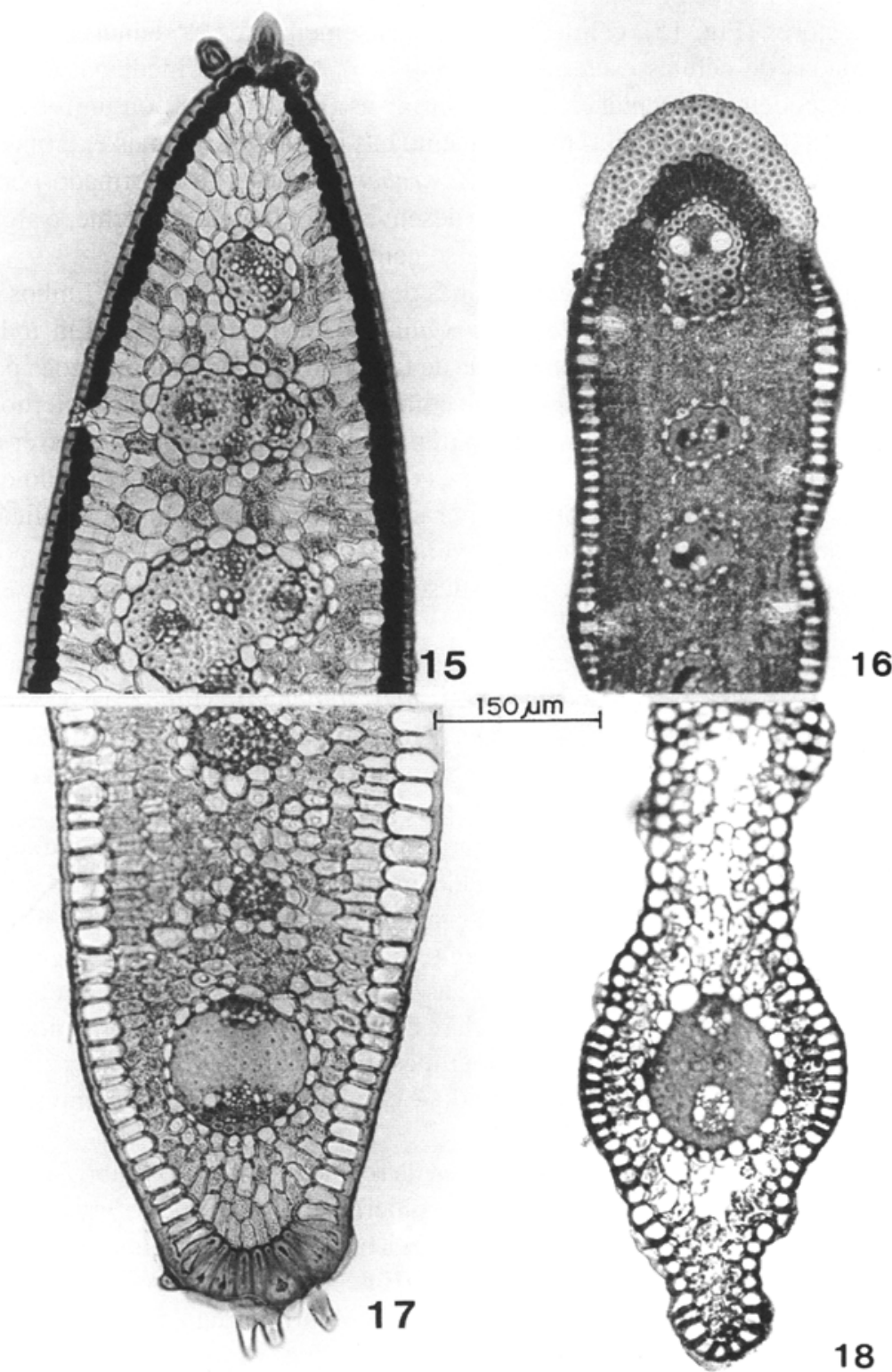

Figuras 15-18. Detalhes de cortes transversais na região mediana do limbro de Xyris pilosa (Fig. 15), X. paraensis (Fig. 16), X. archeri (Fig. 17) eX. savanensis (Fig. 18), mostrando um dos bordos foliares e parte do mesofilo. 

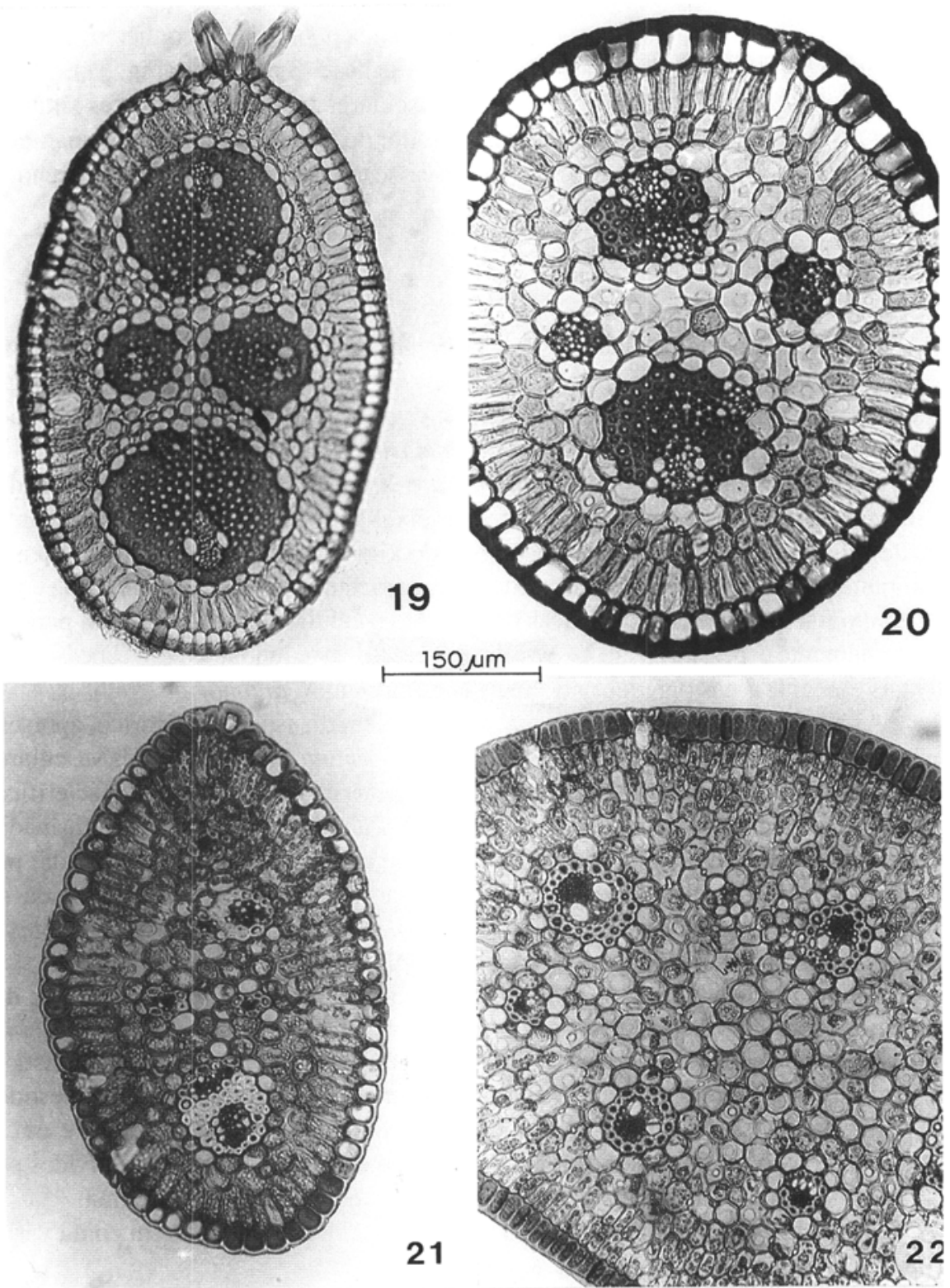

Figuras 19-22. Detalhes de cortes transversais na região basal da lâmina foliar de X. minarum (Fig. 19), X. tortula (Fig. 20), X. anamariae (Fig. 21) e X. spinulosa (Fig. 22). Notam-se lâminas cilíndricas de organização variada. 
mente aos feixes vasculares, na região adjacente ao floema, observam-se 1-3 camadas de células esclerificadas (Fig. 31) ou apenas 1 camada (Fig. 32). Na porção interna do agrupamento vascular, adjacente aos polos de xilema, podem ser reconhecidas muitas camadas de células esclerificadas (Fig. 32), ou apenas 2-3 camadas (Fig. 31).

Nas figuras 33-35 notam-se unidades vasculares formadas por feixes simples, com 1-2 camadas de células esclerificadas ao redor do floema e xilema. Externamente aos feixes fibro-vasculares (Fig. 33-35) observa-se uma bainha de natureza parenquimática, portadora de cloroplastídeos (setas).

\section{Discussão}

Dentre as espécies estudadas, 10 apresentam limbos ensiformes, em corte transversal, (Xyris melanopoda, X. pilosa, X. archeri, X. tortilis, X. savanensis, X. ptery'goblephara, X. paraensis, X. obcordata, X. platystachia e X. hymenachne) e 4 limbos elípticos a cilíndricos (Xyris spinulosa, X. anamariae, X. minarum e X. tortula).

As lâminas cilíndricas de $X$. spinulosa e $X$. anamariae apresentam unidades vasculares formadas predominantemente por feixes simples envolvidos por 1-2 camadas de células esclerificadas, tanto na região do xilema como na do floema. Diferem entretanto, no número de unidades vasculares presentes (4-5 em X. anamariae e 6-7 em $X$. spinulosa) e nas características da epiderme: células retangulares com paredes uniformemente espessadas, em X. spinulosa, e células arredondadas com espessamento mais evidente e nas paredes periclinais externas, em $X$. anamariae.

As lâminas de Xyris minarum e $X$. tortula, além do aspecto cilíndrico, apresentam em comum apenas 4 unidades vasculares. Em X. minarum, as unidades vasculares são formadas por feixes simples e apresentam muitas camadas de células esclerificadas (6-8) na região do xilema. Em $X$. tortula, 2 das unidades vasculares são formadas por feixes simples e 2 por feixes compostos, sendo a região xilemática envolvidas por apenas 1-3 camadas de fibras. As folhas dessas duas espécies diferem ainda na organização da epiderme que, em X. minarum, é formada por células menores e apresentam tricomas tectores em um dos "bordos".

Algumas das espécies, portadoras de limbos ensiformes, distinguem-se das demais pela ocorrência de caracteres anatômicos particulares. É o caso de X. pterygoblephara, com unidades vasculares organizadas em duas séries e mesofilo característico, formado apenas por células braciformes, deX. paraensis com bordos foliares revestidos por várias camadas de células esclerificadas e limbos de contorno sinuoso e de $X$. melanopoda com parênquima aqǘf́ero no mesofilo e feixes vasculares envolvidos por várias camadas de células esclerificadas, particularmente na região do floema.

Os demais limbos foliares podem ser reconhecidos levando-se em conta várias características.

Xyris platystachia, X. tortilise $X$. pilosa apresentam unidades vasculares dispostas em 1-2 séries, mas diferem entre si na organização dessas unidades (feixes compostos em X. pilosa, feixes simples em X. tortilis e em proporção similar em X. platystachia).X. platystachia distingue-se, ainda por apresentar células epidérmicas de tamanho variado, 

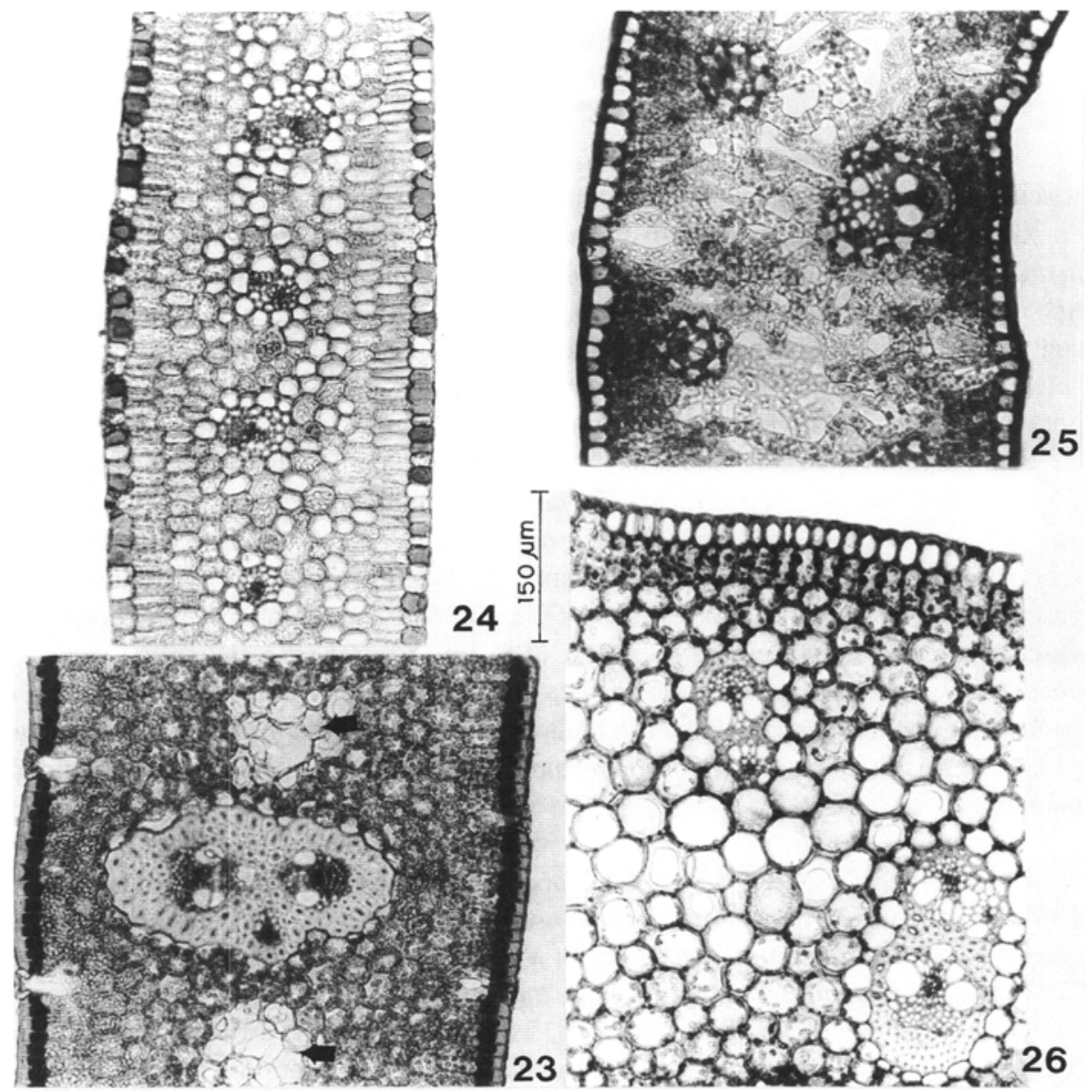

Figuras 23-26. Detalhes de cortes transversais na região basal do limbo de X. melanopoda (Fig. 23), X. tortilis (Fig. 24), X. pterygoblephara (Fig. 25) e X. platystachia (Fig. 26). Observam-se variações na estrutura do mesofilo, epiderme e feixes vasculares. As setas indicam parênquima aqüifero. 
com espessamento evidente nos bordos, e pela presença de unidades vasculares envolvidas por 1-4 camadas de células esclerificadas, na região do floema.

$X$ rris pilosa e $X$. tortilis diferem entre si no número de unidades vasculares presentes no limbo (5-6 em $X$. pilosa e mais de 25 em $X$. tortilis), no número de camadas de células esclerificadas envolvendo o xilema (3-8 em X. pilosa e 1-2 em $X$. tortilis) e no tipo de parênquima do mesofilo (paliçádico evidente em $X$. tortilis e pouco desenvolvido em $X$. pilosa). Diferem, ainda, no tipo de unidades vasculares presentes nos bordos de seus limbos (unidades iguais de feixes simples em $X$. tortilis e diferentes entre si em $X$. pilosa, sendo uma formada por feixe simples e outra por feixe composto).

Em X. savanensis, X. hymenachne, X. obcordata e X. archeri as unidades vasculares são, predominantemente, simples com poucas células esclerificadas ao redor do xilema (1-3 camadas) e se dispõem em uma única série. $X$. savanensis e $X$. hymenachne diferem das demais pela ocorrência de contorno irregular do limbo e pelo tipo de mesofilo: parênquima paliçádico pouco desenvolvido e células braciformes no centro. Diferem entre si nas características epidérmicas (células com papilas em $X$. savanensis) e no tipo de unidades vasculares, presentes nos bordos foliares: compostas por vários feixes, envolvidos por 3-4 camadas de células esclerificadas, em X. savanensis, e simples com apenas 1 camada externa de células esclerificadas, em X. hymenachne.

Os limbos de $X$. obcordata e $X$. archeri são semelhantes quanto ao revestimento dos bordos (células espessadas e tricomas tectores) e organização das unidades vasculares encontradas nessa região (uma unidade formada por um único feixe vascular e a outra composta por vários). Diferem, entretanto, no número de unidades vasculares encontrados em seus limbos (7-9 em $X$. archeri e mais de 15 em $X$. obcordata), no tipo de células epidérmicas (bastante desenvolvidas em $X$. archeri e com espessamento periclinal externo mais evidente em $X$. obcordata), e na organização do mesofilo: lacunoso em $X$. obcordata e com parênquima paliçádico subepidérmico em $X$. archeri.

Com base no número de unidades vasculares, presentes no limbo, é possível reconhecerem-se dois grupos, entre as espécies estudadas: um com número superior a 15 (X. paraensis, X. obcordata, X. savanensis, X. tortilis, X. pterygoblephara e $X$. platystachia) e outro com número inferior a 10 (X. melanopoda, X. archeri, X. pilosa, $X$. tortula, $X$. minarum, $X$. spinulosa e $X$. anamariae).

De uma maneira geral, limbos com 15 ou mais unidades vasculares apresentam predominantemente feixes simples, com poucas camadas de células esclerificadas, ao redor do tecido xilemático (1-3), além de bainhas parenquimáticas bastante desenvolvidas ao redor dos feixes fibro-vasculares, portadoras de cloroplatídeos. Nesse caso, as plantas exibem porte reduzido $(3-5 \mathrm{~cm})$ e crescem em locais extremamente úmidos, à excessão de $X$. pterygoblephara, com 10-20 cm encontrada em substratos mais secos.

Os limbos com número de unidades inferior a 10 apresentam predominantemente feixes compostos e/ou várias camadas de células esclerificadas ao redor do xilema, notando-se inclusive um maior número de camadas celulares esclerificadas (6-8) em limbos portadores de poucos feixes vasculares (4), como é o caso de X. minarum. As 

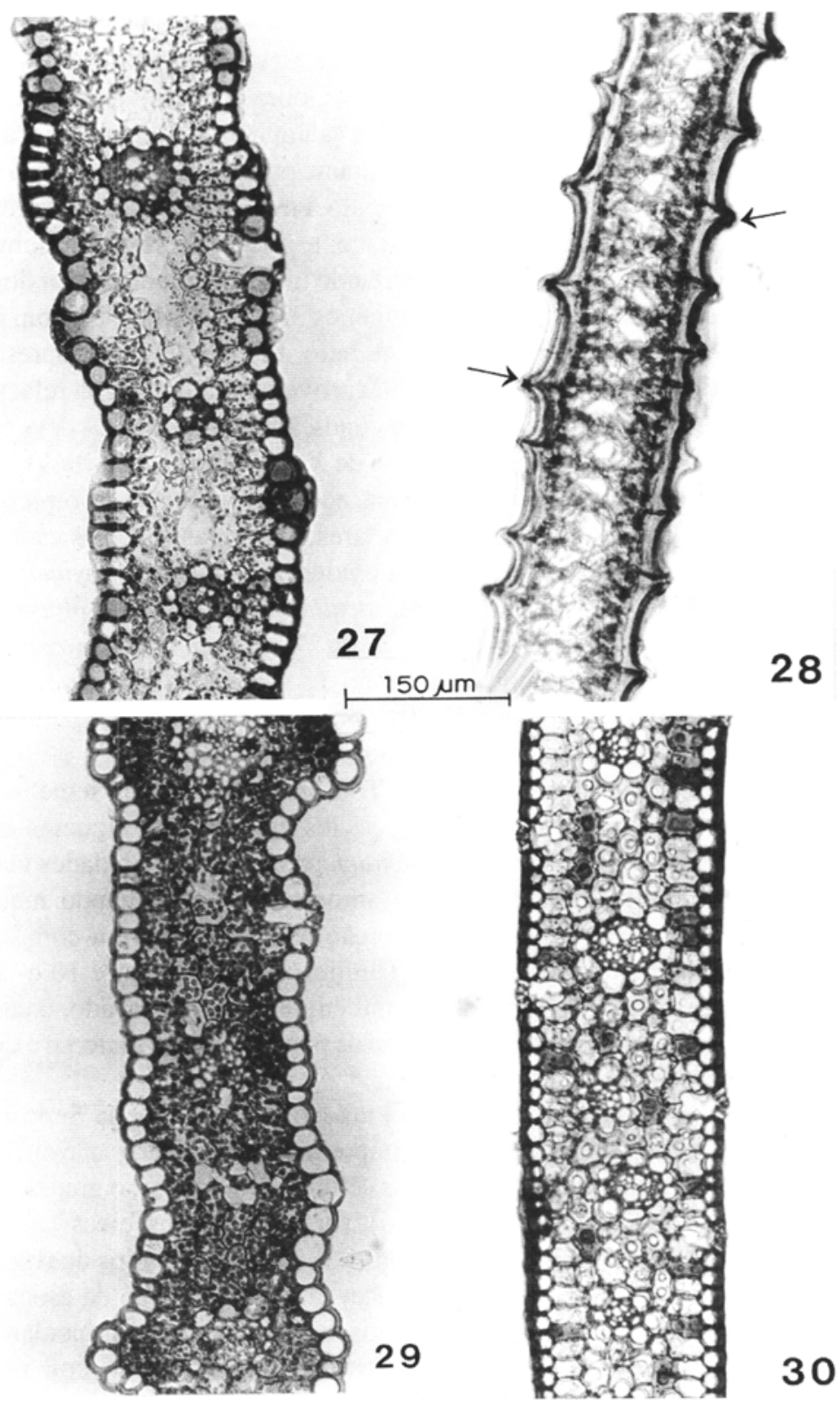

Figuras 27-28. Detalhes de cortes transversal e longitudinal na região mediana do limbo de $X$. savanensis. Observam-se projeções epidérmicas (setas). Figuras 29-30. Detalhes de cortes transversais na região mediana do limbo de $X$. obcordata. Nota-se o contorno sinuoso do limbo na figura 29. 
espécies, com essas características foliares, apresentam entre 5-10 $\mathrm{cm}$ de altura e crescem em substratos mais secos.

Tais observações podem sugerir a ocorrência de duas formas de especialização, nos limbos dos representantes de Xyris que, embora habitem preferencialmente terrenos brejosos na Serra do Cipó, estão sujeitos a um período anual de seca durante o qual, certamente, a água torna-se um fator limitante para a vegetação. Como resposta a esse tipo de pressão ambiental pode ter ocorrido, em algumas espécies, redução no número de unidades vasculares, com consequente fusão de feixes e aumento na quantidade de tecidos esclerificados, possibilitando um crescimento maior dos indivíduos, além de seu estabelecimento em locais menos úmidos. Os limbos, com pequena quantidade de tecidos mecânicos e grande número de unidades vasculares, podem representar outro tipo de resposta eficiente no aproveitamento da água relacionada a processos metabólicos, utilizados apenas em condição de estresse.

Num estudo de revisão sobre a anatomia de Xyris, Tomlinson (1969) descreve, de uma maneira geral, a organização das folhas no gênero e separa os representantes estudados, com base em alguns caracteres foliares. Dentre as espécies estudadas no presente trabalho, Tomlinson (1.c.) analisa a epiderme foliar de $X$. hymenachne, $X$. melanopoda, $X$. minarum, $X$. savanensis, $X$. tortula, $X$. archeri e $X$. platystachia; a distribuição dos feixes vasculares nas folhas de $X$. melapoda, $X$. savanensis, $X$. hymenachne e $X$. minarum; a proporção entre feixes vasculares simples e compostos nas folhas de $X$. tortula, $X$. savanensis, $X$. hymenachne $X$. minarum; e o número total de feixes encontrados nas folhas de $X$. minarum e $X$. hymenachne.

Embora os resultados apresentados por Tomlinson (1.c.) sejam semelhantes aos observados no presente trabalho, para as espécies em questão, algumas exceções devem ser mencionadas. É o caso de X. hymenachne, com 10-20 unidades vasculares predominantemente simples, descritas pelo autor como apresentando mais de 20 feixes simples e compostos, em igual proporção e de $X$. minarum com apenas 2 unidades vasculares simples que, segundo Tomlinson, exibem entre 10 e 20 feixes simples e compostos em igual proporção. Também deve ser destacado, o caso de $X$. savanensis com células epidérmicas portadoras de papilas que, no material examinado pelo autor, não apresentam essa característica.

Wanderley (1992), num estudo sobre a taxonomia de Xyris da Serra do Cipó, aponta alguns aspectos foliares que considera importante na caracterização das espécies. São eles: o tipo de espessamento periclinal das células epidérmicas, o grau de compactação do mesofilo (compacto, frouxo e \pm frouxo), a organização dos feixes vasculares ( 1 , 1-2 ou 2 séries) e o grau de fusão desses feixes (1, 2-3 ou + de 3 polos de floema).

Os resultados apresentados por Wanderley (l.c.), para o tipo de espessamento das células epidérmicas e para a organização dos feixes vasculares, coincidem com os descritos para as espécies estudadas no presente trabalho. Entretanto, com relação ao grau de fusão dos feixes vasculares, observou-se predominância de feixes simples em $X$. archeri, $X$. paraensis, $X$. hymenachne, $X$. savanensis, $X$. minarum e $X$. spinulosa e, nos materiais observados por Wanderley (l.c.), essas espécies apresentaram feixes formados por 2-3 polos de floema. 

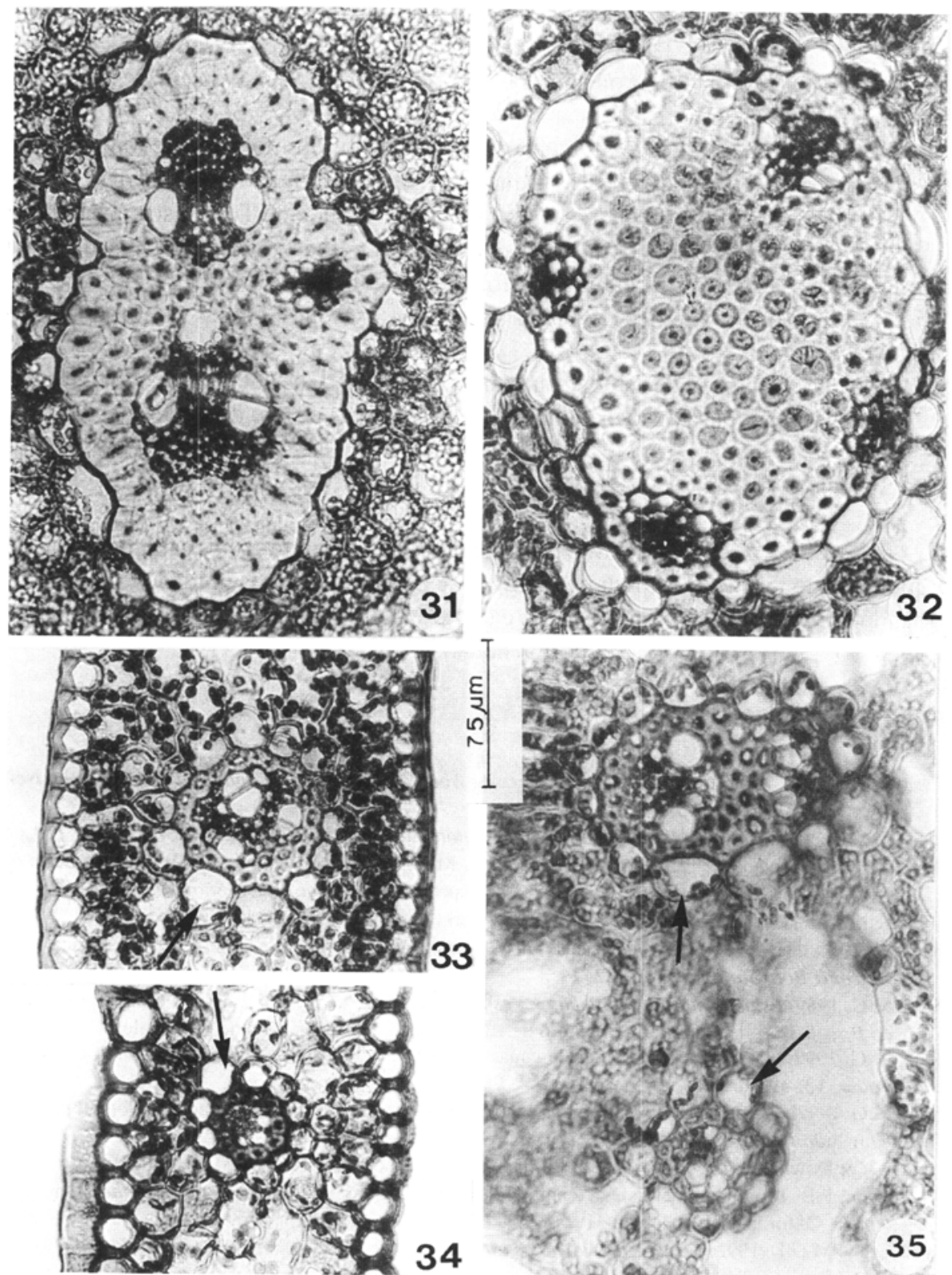

Figuras 31-35. Detalhes de feixes vasculares encontrados nas lâminas foliares de Xiris melanopoda (Fig. 31), X. pilosa (Fig. 32), X. obcordata (Fig. 33), X. savanensis (Fig. 34) e X. pterygoblephara (Fig. 35), mostando unidades vasculares compostas por 3 feixes (Fig. 31) e 4 feixes (Fig. 32), e unidades vasculares formadas por feixes isolados (Fig. 33-35). As setas indicam a bainha parenquimática portadora de cloroplastídeos. 
Segundo Sajo (1989, 1992b), dependendo da região do limbo considerada, encontram-se variações tanto no número de série de feixes vasculares como no predomínio de feixes simples ou compostos, pois ocorrem fusões vasculares laterais e frontais em porções foliares mais apicais.

Talvez por esse motivo, alguns dos resultados obtidos no presente trabalho não coincidam com os indicados por Tomlinson (1969) e por Wanderley (1992).

Finalmente, é importante ressaltar que tanto o estudo de Tomlinson (l.c.) como o de Wanderley (l.c.) têm como objetivo apontar características foliares úteis na definição das espécies. Entretanto, conforme comentado por Wanderley (l.c.) e por Sajo $(1989,1992 b)$ algumas espécies de Xyris exibem lâminas de organização bastante variável.

Daí a necessidade de estudos anatômicos foliares mais detalhados com o intuito de se reconhecerem as possíveis tendências adaptativas dentro do gênero.

\section{Conclusões}

As folhas das espécies de Xyris estudadas diferem, entre si, nas características da epiderme e do mesofilo e no número e grau de agrupamento das unidades vasculares. Quando analisadas em conjunto, essas características podem indicar formas de especialização foliar, relacionadas à deficiência hídrica.

\section{Referências bibliográficas}

Carlquist, S. 1960. Anatomy of Guyana Xyridaceae: Abolboda, Orectanthe and Achlyphylla. Mem. New York bot. Gdn 10(2): 65-117.

Dop, P. \& Gautié, A. 1909. Manuel de techinique botanique, Paris, F.R. de Rudeval.

Giulietti, A.M.; Menezes, N.L.; Pirani, J.R.; Meguro, M. \& Wanderley, M.G.L. 1987. Flora da Serra do Cipó, Minas Gerais: Caracterização e lista de espécies. Bolm. Bot., Univ. São Paulo 9: 1-152.

Johansen, D.A. 1940. Plant microtechnique. New York, Mc Graw-Hill Bood Co.

Krall, R. 1988. The genus Xyris (Xyridaceae) in Venezuela and contiguous northern South America. Ann. Missouri Bot. Gard. 75: 522-722.

Sajo, M.G. 1989. Estudos morfoanatômicos em espécies de Xyris L. (Xyridaceae) dos Campos Rupestres do Brasil. Tese de Doutorado. Instituto de Biociências da Universidade de São Paulo.

Sajo, M.G. 1992a. Organização vascular do caule em Xyris L. (Xyridaceae). Bolm. Botânica, Univ. São Paulo, 13: 49-66.

Sajo, M.G. 1992b. Estudos morfoanatômicos em órgãos foliares de Xyris L. (Xyridaceae). Bolm. Botânica, Univ. São Paulo, 13: 67-86.

Smith, J. \& Downs, R. 1968. Xyridaceae. In: Hoehne, F.C. (ed.) Flora brasilica 9(2): 1-209.

Tomlinson, P.B. 1969. Commelinales - Zingiberales. In: Metcalfe, C.R. (ed). Anatomy of the Monocotyledons. Oxford, At the Claredon Press. v.3.

Wanderley, M.G.L. 1992. Estudos taxonômicos no gêneroXyris L. (Xyridaceae) da Serra do Cipó, Minas Gerais, Brasil. Tese de Doutorado. Instituto de Biociências da Universidade de São Paulo. 